\title{
Das revistas aos livros: Machado de Assis, Jules Verne e seus editores ${ }^{1}$
}

\author{
Lucia Granja ${ }^{2}$
}

\begin{abstract}
Resumo: Este artigo estuda alguns aspectos da relação entre dois editores (Baptiste-Louis Garnier e Pierre-Jules Hetzel) e dois de seus escritores (respectivamente, Machado de Assis e Jules Verne), uma dupla na França e outra no Brasil. O objetivo da pesquisa é demonstrar que as ações editoriais de Baptiste-Louis Garnier, se comparadas às de grandes editores franceses de meados do século XIX, revelam a circulação de métodos para a produção de conteúdo literários e para a ampliação das formas de circulação dos textos de ficção, primeiramente nos periódicos e, depois, nos livros. Adota-se, nesta pesquisa, a perspectiva de que uma literatura nacional não é apenas fruto da produção de um país, mas toma forma como resultado de contatos entre várias partes do globo, trocas culturais e ações de mediadores. Nesse processo, as tensões entre editores e escritores, comparativamente estudados, revelam novidades sobre suas trajetórias de consagração e de aquisição de capital simbólico, na conceituação de Pierre Bourdieu.
\end{abstract}

Palavras-Chave: Baptiste-Louis Garnier; edição; literatura mundial; Machado de Assis; capital simbólico.

Baptiste-Louis Garnier, o irmão caçula dos editores Garnier de Paris, livreiro instalado no Brasil desde os anos 1840, assumiu, no final dos anos 1850, a vocação editorial de sua empresa. Para isso, separou-se comercialmente de seus irmãos, mas apenas no que se refere ao negócio da edição de livros brasileiros. ${ }^{3}$

História interessante essa da separação, pois sua sequência mostra que Baptiste-Louis Garnier adotou novos modelos de trabalho, inclusive em parceria com Hetzel na publicação de Julio Verne no Brasil. ${ }^{4}$ Isso reafirma que as ações editorias de Garnier no Brasil devem ser

\footnotetext{
${ }^{1}$ Este artigo foi apresentado, em primeira versão, como "comunicação oral", no congresso "A imprensa francófona nas Américas", realizado na UNESP, campus de São Paulo capital, em novembro de 2018.

${ }^{2}$ Doutora em Teoria e História Literária pela UNICAMP (1997). Professora de Literatura e Cultura Brasileiras na UNICAMP, desde fevereiro de 2020. Foi professora de Literatura e Cultura Brasileiras na UNESP (campus de São José do Rio Preto), entre 2004 e 2020. Brasil. E-mail: lgranja@unicamp.br Orcid: http://orcid.org/0000-00022695-5345

${ }^{3}$ Essa informação foi confirmada, em entrevista, por Danièle Garnier, segunda esposa de Bernard Garnier (19272010), último membro da família a dirigir os negócios dos Editores Garnier, até 1983. Bernard Garnier é filho de Auguste-Pierre Garnier, o sobrinho-neto dos editores Garnier do século XIX que assumiu definitivamente os negócios da família aos 26 anos, em 1911, após o falecimento de François-Hippolyte Garnier.

${ }^{4}$ Valéria Cristina Bezerra tem estudado as relações entre os dois editores, Garnier e Hetzel, desde 2018, embora suas descobertas ainda não estejam publicadas.
} 


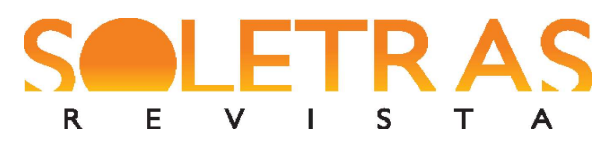

comparadas às de grandes editores franceses dos anos 1850 e 60, além de revelar a circulação internacional dos métodos para a produção de conteúdos e para ampliação das formas de circulação do impresso. No caso de Baptiste-Louis Garnier, há ainda a vantagem de se suplantar a ideia romântica do editor que construiu sozinho seu reino de livros, de altos préstimos para a literatura brasileira.

Voltando ao rompimento entre os “Garnier Frères", até há poucos anos, contávamos sobretudo com a versão de Hallewell (2005, p. 119), que nos fala de um rompimento comercial entre os irmãos Garnier, por volta de 1864-1865. Mais recentemente, Jean-Yves Mollier argumentou que essa ruptura teria sido uma mera mudança de razão social, por motivações políticas decorrentes da imagem negativa projetada pela França no Brasil e nas Américas em geral, após a intervenção no México, em 1863 (MOLLIER, 2018, p. 33-34). No final dessa história, documentos recentemente encontrados sugerem uma sutileza a ser acrescida à tese da separação entre as casas Garnier francesa e brasileira, válida para o que se refere ao negócio dos impressos em português: Auguste e François-Hippolyte passaram a investir no mercado dos livros em português, sobretudo de gramáticas e dicionários, via Portugal, enquanto Baptiste-Louis agia no Brasil. Um exemplo é o contrato assinado entre os Irmãos Garnier de Paris e Arnaldo Gama, do Porto, para a elaboração de um dicionário Português-Francês, contrato de 13 de junho de $1863 .{ }^{5} \mathrm{Na}$ mesma época, outro lado do Atlântico, Baptiste-Louis Garnier dedicou-se, como os irmãos, a edições escolares e manuais, que tinham boas vendas, mas passou também a atuar como um editor moderno (CHARTIER e MARTIN, 1990, p. 6), aquele que faz pesquisa de manuscritos, descobre autores e compõe um fundo próprio, ao invés do comércio de livros variados, rumando para a especialização do catálogo e criação de coleções que passaram a dar imagem e clientela à sua casa editorial.

Um dos primeiros investimentos importantes de Baptiste-Louis Garnier no negócio da edição foi a publicação de periódicos. Valéria Guimarães descobriu recentemente que o editor franco-brasileiro passou a dirigir o jornal L'Écho du Brésil et de l'Amérique du Sud, a partir de 11 de março de 1860 (GUIMARÃES, 2017, p. 111), o que se deu após a morte de Altève Aumont (1835-1860), que estivera à frente do jornal desde a sua fundação, no Rio de Janeiro, em maio de 1859. Antes disso, já sabíamos que Garnier se empenhara na construção de um periódico dedicado, como se apresenta no prospecto aos leitores, “aos interesses domésticos

\footnotetext{
${ }^{5} \mathrm{O}$ documento consta dos "Fundos Garnier" do IMEC - Institut Mémoire de L'Édition Contemporaine, Abbaye d'Ardennes, Saint-Germain-la-Blanche-Herbe, França.
} 


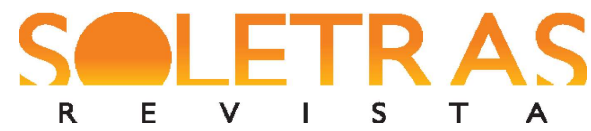

N. $40-2020.2$ - LUCIA GRANJA

das famílias brasileiras", o Jornal das Famílias (1863-1878). Esse periódico funcionou, conforme declarado em seu programa, como um continuador aperfeiçoado da Revista Popular (1858-1862), também da propriedade de Baptiste-Louis Garnier.

Casos comparáveis, deste lado do Atlântico estavam Baptiste-Louis Garnier, Joaquim Maria Machado de Assis e o Jornal das Famílias, periódico que auxiliou o livreiro estabelecido e editor em afirmação a amealhar os capitais econômico e literário necessários ao mercado do livro, bem como auxiliou o então jovem escritor Machado de Assis a acumular o capital simbólico necessário à publicação de sua ficção, na forma livro; do outro lado, estavam PierreJules Hetzel e Julio Verne, também envolvidos com alguns periódicos ilustrados, que lhes possibilitaram o acúmulo dos capitais econômico e simbólico necessários para atuar no exigente mercado editorial francês do livro, na segunda metade do século XIX, sempre chez Hetzel.

As revistas para as quais Machado de Assis e Jules Verne produziram ficção surgiram, no Brasil e na França, nos anos 1850-1860. O Jornal das Famílias (janeiro de 1863) era impresso em Paris, na tipografia de Simon \& Raçon, especializada na edição em língua portuguesa. O Magasin d'éducation et de récreation e o Musée des familles eram publicados em Paris, e tiveram diferentes fases. Nesses periódicos, colaborou Jules Verne e Hetzel teve alguma forma de interferência e controle sobre essa produção, conforme nos noticia Edmar Guirra:

Qualquer que seja a pesquisa empreendida sobre a obra de Jules Verne, não se pode deixar de reservar interesse ao seu encontro com o editor Pierre-Jules Hetzel (...)

(...) o editor capaz de verificar o valor literário de Verne [Hetzel], caucionado por um público ávido pela ciência, será promotor de uma renovação da visão editorial sobre a literatura para crianças e jovens e integrará Verne à equipe fundadora do Magasin d'Éducation et de Récréation, em 1864. No entanto, (...) antes de 1862, data do primeiro contrato de Verne, o escritor já havia realizado diversas tentativas de entrada no universo da literatura, escrevendo poemas, textos dramáticos, novelas para o periódico Musée des familles e um artigo crítico sobre o Salão de 1857. (GUIRRA, 2016, p. 26)

No momento em que encontramos Jules Verne ou Machado de Assis escrevendo para os periódicos ilustrados em questão, eles configuram-se para ambos os jovens literatos como espaços para publicação de textos experimentais de ficção. Ensaiando ali narrativas curtas, essas 


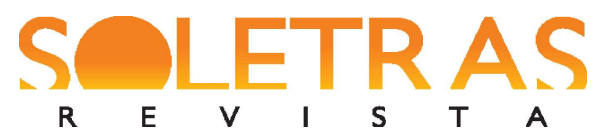

N. $40-2020.2$ - LUCIA GRANJA

publicações funcionaram como trampolins para outras, na forma "livro", e que garantiram a expansão das atividades editoriais de Hetzel e de Garnier, bem como para a passagem dos próprios escritores dos jornais aos livros, como demostrará a análise comparada de documentos encontrados, os contratos assinados entre as duplas Hetzel-Verne e Baptiste-Louis GarnierMachado de Assis. Parece claro que, em ambos os casos, os editores souberam reconhecer nos temas experimentados pelos escritores nos periódicos aquilo que lhes renderia, mais tarde, romances publicados pelas próprias editoras de Pierre-Jules Hetzel e Baptiste-Louis Garnier.

No Brasil, Baptiste-Louis Garnier engajava-se na construção de uma revista dedicada “aos interesses domésticos das famílias brasileiras”, o Jornal das Famílias (1863-1878), o qual funcionou, conforme declarado em seu programa, como um continuador aperfeiçoado da Revista Popular (1858-1862), também da propriedade de Baptiste-Louis Garnier. No primeiro número (janeiro de 1863), a mensagem “Aos nosso leitores” trouxe a seguinte apresentação dessa empreitada:

"Aos nossos leitores

O benigno acolhimento com que foi sempre recebida, durante cinco anos completos, a Revista Popular, já pelo público desta Corte, já pelo das demais províncias do Império, é credor da cordial gratidão que, com prazer, lhe tributamos.

(...)

Hoje, mais corajoso do que dantes, (...) resolvemos, sob o título de Jornal das Famílias, melhorar a nossa publicação. O Jornal das Famílias, pois, é a mesma Revista Popular doravante mais exclusivamente dedicada aos interesses domésticos das famílias brasileiras.

São os seus colaboradores os mesmos distintos cavalheiros a quem tanto deve a Revista, acrescentando outros que tivemos a honra e a fortuna de angariar.

Mais do que nunca dobraremos os nossos zelos na escolha dos artigos que havemos de publicar, preferindo sempre os que mais importarem ao país, à economia doméstica, à instrução moral e recreativa, à higiene, numa palavra, ao recreio e utilidade das famílias.

O Jornal das Famílias sai uma vez por mês nitidamente impresso em Paris, e dará aos assinantes, no correr da publicação, gravuras, desenhos à aquarela coloridos, moldes de trabalho de crochê, bordados, lã, tapeçaria, figurinos de modas, peças de música inéditas etc., para o que tem contratado naquela capital os melhores artistas.

Certa de que assim preencherá uma falta, geralmente observada, com esta publicação, e contando com o benigno acolhimento público que mereceu a Revista Popular, compromete o seu mais fiel desempenho nesta empresa.

A Redação. 


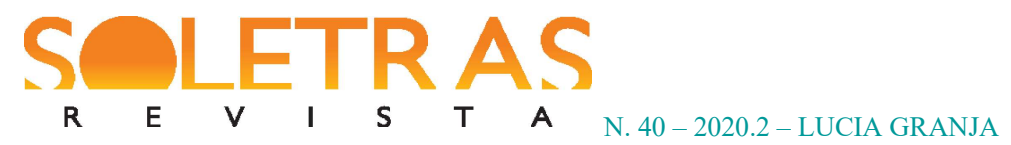

(Jornal das Famílias, janeiro de 1863, p. 1, Disponível em: https://bndigital.bn.gov.br/hemeroteca-digital/, grifos nossos)

Machado de Assis está entre os distintos cavalheiros que o Jornal das Famílias “angariou” para sua redação, na passagem da Revista Popular à publicação que a sucedeu, publicação mais "corajosa" diante do acolhimento do público e "doravante mais exclusivamente dedicada aos interesses domésticos das famílias brasileiras". $\mathrm{Na}$ mesma mensagem, está o anúncio da qualidade com que ali seriam publicados textos, desenhos, moldes, partituras etc., "nitidamente impressos em Paris", o que também rende uma observação importante. Machado de Assis, em início de carreira, enquanto abria mais terreno para a literatura brasileira e se tornava o principal produtor de ficção desse periódico de Garnier, oferecia, como cronista e crítico literário, importante apoio às publicação dos textos brasileiros na editor de Baptiste-Louis Garnier, por meio da recepção crítica dos mesmos. Na série de crônicas “Ao Acaso", publicadas no Diário do Rio de Janeiro entre junho de 1864 e meados de 1865, o jovem escritor fala-nos várias vezes das ações comerciais e edições de Garnier, contribuindo para a consolidação da linha editorial que Baptiste-Louis abria para a Literatura Brasileira, a qual resultaria, inclusive, em uma coleção que, ainda hoje, corresponde ao cânone da poesia brasileira denominada "árcade" e "romântica" (GRANJA e SANTANA Jr., 2019, p. 55-72). Dentre as quarenta e oito crônicas que Machado de Assis publicou na série "Ao acaso", oito discorrem em algum momento sobre as atividades de Garnier. Em 17 de outubro de 1864, aparece um comentário longo sobre o livro de Gonçalves de Magalhães, que merece destaque:

Os Cantos fúnebres encontrarão da parte do público brasileiro o acolhimento a que têm direito. Tanto mais devem procurar o novo livro quanto que este volume é o sexto da coleção das obras completas do poeta, que o Sr. Garnier vai editar.

$\mathrm{O}$ volume que tenho à vista é nitidamente impresso. A impressão é feita em Viena, aos olhos do autor, garantia para que nenhum erro possa escapar; sendo esta a edição definitiva das obras do poeta é essencial que ela venha limpa de erros.

Um bom livro, uma bela edição, que mais pode desejar o leitor exigente?

(Diário do Rio de Janeiro, Ao Acaso, 17 de outubro de 1864, rodapé, p. 1, acessível em: https://bndigital.bn.gov.br/hemeroteca-digital/, grifos nossos). 
Ao mencionar o novo volume de Gonçalves de Magalhães, o cronista Machado de Assis ressaltou para os seus leitores, nos mesmos termos que o fizera o Jornal das Famílias quase dois anos antes, a impressão nítida, feita na Europa, sem erros, composta sob as vistas do escritor que as acompanhava de perto. O público brasileiro, conforme aconselha o cronista, deveria acolher como é de direito essa obra, o que nos coloca diante da associação entre o editor e o crítico-cronista. Machado de Assis logo seria o ficcionista do Jornal das Famílias, tendo ali publicado cerca de oitenta contos, desde "Frei Simão" em junho de 1864, até o último número do periódico, de dezembro de 1878, com “Dívida extinta". Mas, para além da parceria entre eles, nessa primeira metade dos anos 1860, Machado de Assis e Baptiste-Louis Garnier estavam também em uníssono com produção editorial de outras localidades do globo. Na França, o editor Hetzel previa um desdobramento de publicações periódicas, retomando as histórias que ali haviam aparecido e as republicando em volumes autônomos:

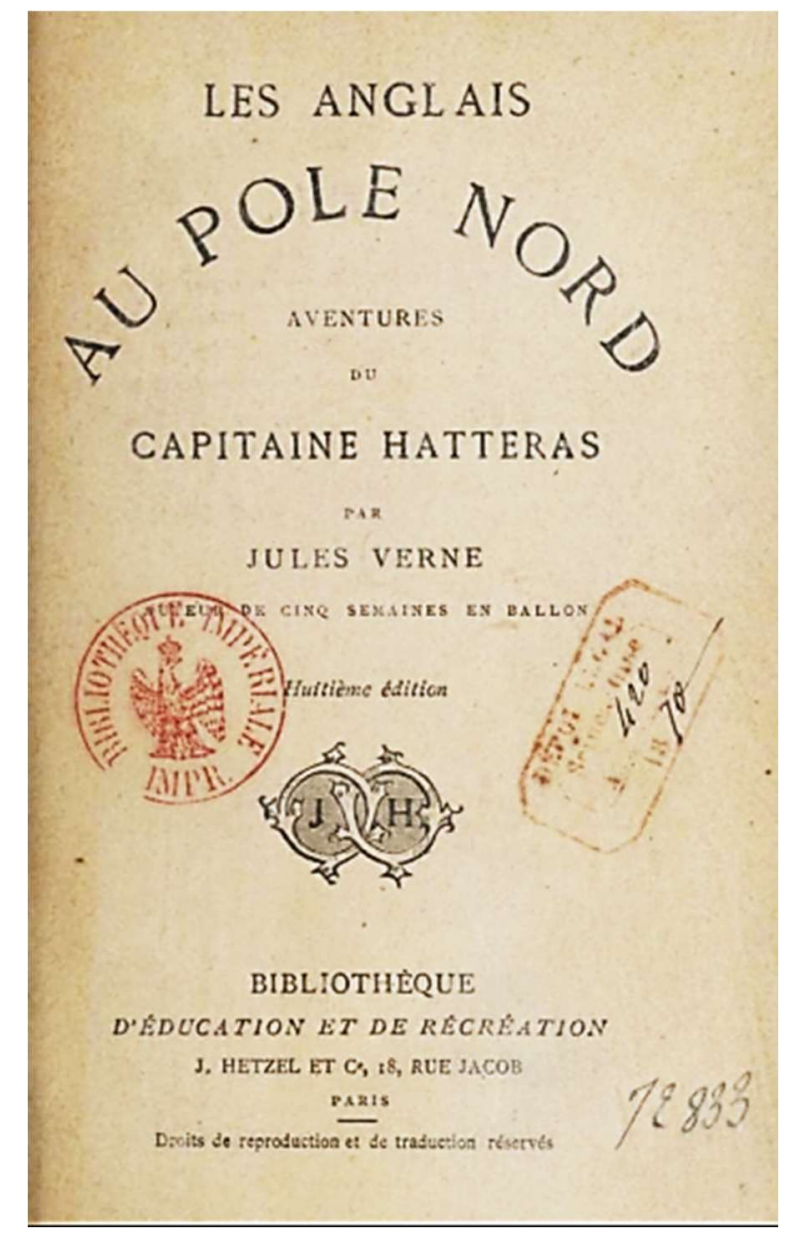

Fig. 1 Capa do romance de Júlio Verne na coleção "Bibliothèque d'Éducation et de Récréation" 
Fonte: gallica.bnf.fr/ Bibliothèque Nationale de France

Ao longo de sua carreira, o editor Hetzel foi progressivamente direcionado suas publicações periódicas para o público juvenil, como forma de ampliar o leque de leitores, até chegar à base do Magasin d'Éducation et de Récréation, onde cabiam romances de temas histórico-científicos, em uma visada didática (GUIRRA, 2016, p. 59). Após várias tentativas de publicação de periódicos nas quais afinava a estratégia da nova revista - educação e recreação, com público ampliado - o encontro de Hetzel com o pedagogo, jornalista, escritor e antigo colega de escola, Jean Macé, deu corpo ao projeto. Em 20 de março de 1864, o primeiro número do Magasin foi publicado e logo a revista dá início a coleções de romances, como a "Bibliothèque illustrée des familles" que se tornaria, na verdade, a "Bibliothèque d'Éducation et de Récréation", onde passaram a ser publicados os romances de Verne, adquirindo esses, mais tarde, a independência da forma livro (GUIRRA, 2016, p 56-61).

Como estratégica editorial, a passagem do periódico ao livro não era exatamente uma novidade. Alguns jornais, depois de publicarem os folhetins, transformavam-nos em livros, aproveitando-se mesmo da composição que havia sido feita para o jornal (WITKOWSKI, 1993, p. 3-10). Nos casos aqui analisados, contudo, essa mutação de veículos aplica-se à construção da carreira de dois ficcionistas que ocupariam posições de destaque no campo. No Brasil, Garnier adotou meios similares aos de Hetzel, considerando os propósitos moral e de entretenimento alegados pela apresentação do Jornal, em janeiro de 1863. Evidentemente, havia interesses propriamente financeiros de Baptiste-Louis Garnier, que, como se disse, à época da criação do Jornal das Famílias, procurava afirmar-se não apenas como comerciante de livros, mas também como editor, atuando em todas as frentes possíveis.

A republicação de textos de ficção trazia rendimento aos esforços dos editores, rendendo-lhes fruto no periódico e no livro. Analisando alguns documentos, vemos como Hetzel e Garnier souberam duplicar em impressos, e lucros, o trabalho das revistas. Ambos os escritores, Verne, que Garnier viria publicar no Brasil (BEZERRA, 2018, p. 89), e Machado foram fixados aos periódicos de seus editores como contistas/novelistas, em uma primeira fase de suas carreiras, aliás rigorosamente contemporâneas. Hetzel, na França, explorou ao máximo essa estratégia. Em contrato assinado entre Hetzel e Verne, datado de 11 de dezembro de 1865, o editor interveio até mesmo na montagem de coletâneas de contos nas quais reuniria textos 
inéditos de Verne e outros saídos no Musée des Familles (1833-1900), periódico que, em sua terceira fase (1843-1882), abrigara, como se disse, desde os anos 1850, a contribuição de Verne como ficcionista.

\begin{abstract}
Art. $8^{\circ}$. Mr Jules Verne publicou no Musée des Familles um certo número de novelas e está autorizado por M. Hetzel a publicar ainda uma por ano; é dito que essas novelas só poderão ser publicadas em volume por M. Hetzel, quer seja na totalidade, quer seja em partes, à escolha de Hetzel, se elas the parecerem ter a natureza para serem reunidas em volume. ${ }^{6}$

(Contrato assinado entre Jules Verne e Pierre-Jules Hetzel em 11 de dezembro de 1865, consultado nos "Fundos Jules Verne", "Seção de Manuscritos" da Bibliothèque Nationale de France, site Richilieu).
\end{abstract}

O documento pode ser verificado no livro de registros de Hetzel, no acervo indicado, onde está o contrato passado a limpo, ou seja, corresponde à versão definitiva do acordo entre editor e escritor. Ele relembra que Verne publicara várias novelas no Musée des familles de Hetzel, e poderia publicar ainda uma por ano, mas observa-se que as novelas (ou contos) poderiam ser reunidos em volume, unicamente sob decisão e seleção do editor. Com pequenas variações, as mesmas condições contratuais repetem-se em outros instrumentos legais assinados entre Hetzel e Verne, o que limita a autonomia do ficcionista, sobretudo no que se refere à passagem de seus escritos de um veículo relativamente efêmero ao livro.

A mesma dinâmica era aplicada às obras de Machado de Assis na revista de Garnier. Um documento nos mostra, porém, que, sob os trópicos, nem todas as condições eram iguais às da dupla de franceses. Abaixo estão a figura e a transcrição de um dos contratos assinados entre Machado de Assis e Garnier que nos restam:

\footnotetext{
6 “Art. $8^{\circ}$. Mr Jules Verne a publié, dans le Musée des Familles, un certain nombre de nouvelles, et est autorisé par Mr. Hetzel à en publier encore une par année; il est dit que ces nouvelles ne pourront être publiées en volume que par M. Hetzel, soit en totalité soit en partie à son choix, si elles lui paraissent de nature à être reunies en volume." (contrato assinado entre Jules Verne e Pierre-Jules Hetzel de 11 de dezembro de 1865, consultado nos "Fundos Jules Verne", Seção de Manuscritos, da Bibliothèque Nationale de France, site Richilieu). Embora eu tenha consultado os contratos firmados entre Hetzel e Verne na referida biblioteca, foi a leitura da tese de doutorado de Edmar GUIRRA, A trajetória de Jules Verne: a Arte, o escritor e seu editor, que me chamou a atenção para a rigorosa simultaneidade, para as semelhanças e diferenças entre as duplas Verne/Hetzel e Machado/Garnier. Foi nessa tese, inclusive, que li, pela primeira vez, a transcrição de três dos contratos assinados pela dupla francesa.
} 


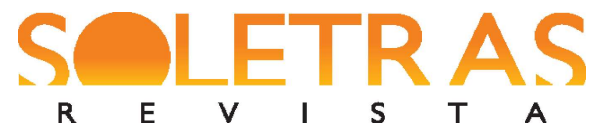

N. $40-2020.2$ - LUCIA GRANJA

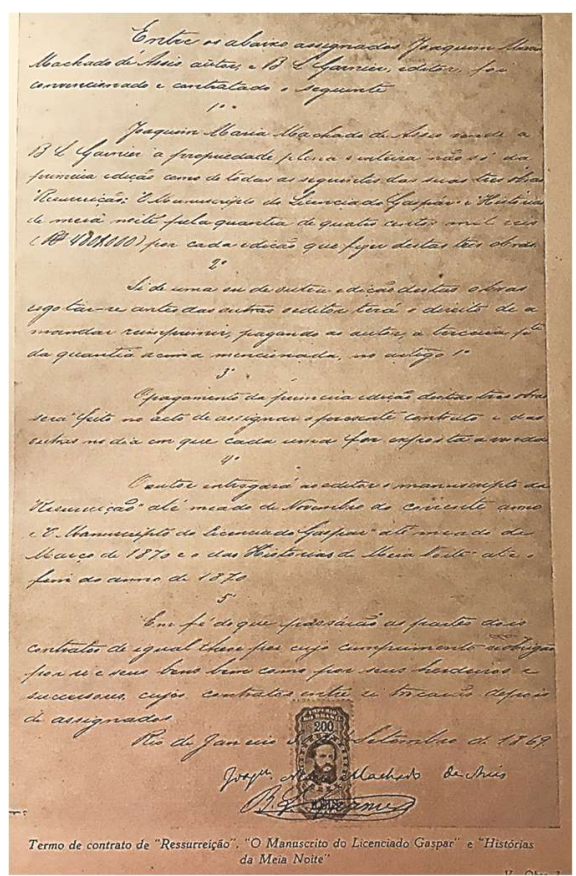

Fig. 2 Catálogo da Exposição Machado de Assis, de 1839, p. 181.

Entre os abaixo assinados, Joaquim Maria Machado de Assis, autor, e B. L. Garnier, editor, foi convencionado e contratado o seguinte:

$1^{\circ}$

Joaquim Maria Machado de Assis vende a B. L. Garnier a propriedade plena e inteira não só primeira edição como todas as seguintes das suas três obras "Ressurreição", "O Manuscrito do Licenciador Gaspar" e "Histórias da MeiaNoite" pela quantia de quatrocentos mil reis (Rs 400\#000) por cada edição que fizer dessas três obras.

\section{$2^{\circ}$}

Se uma ou de outra edição destas obras esgotar-se antes das outras o editor terá o direito de a mandar reimprimir, pagando ao autor a terceira parte da quantia acima mencionada no artigo $1^{\circ}$.

$$
3^{\circ}
$$

O pagamento da primeira edição destas três sobras será feito no ato de assinar o presente contrato e das outras no dia em que cada uma for exposta a venda.

$4^{\circ}$

O autor entregará ao editor o manuscrito de "Ressurreição" até meados de novembro do corrente ano e "O Manuscrito do Licenciado Gaspar" até meados de março de 1870 e o das "Histórias da Meia-Noite" até o fim do ano de 1870 .

\section{$5^{\circ}$}

Em fé do que passarão as partes dois contratos de igual teor por cujo cumprimento se obrigarão por si seus bens e seus herdeiros e sucessores, cujos contratos entre si trocarão depois de assinados.

Rio de Janeiro, 30 de setembro de 1869 
(Catálogo da Exposição Machado de Assis, de 1839, transcrição na página 178 e imagem na página 181)

Essa é a versão limpa do contrato, colhida nos papeis do escritor, pois a mostra em que esse documento foi exposto, e que produziu o catálogo que nos serve de fonte, foi alimentada pela coleção particular de Laura Costa Leitão de Carvalho, sobrinha-neta de Carolina Xavier de Novais e, portanto, herdeira universal do casal Machado de Assis. O contrato mereceria ser analisada por completo, devido à riqueza de informações que apresenta, sobretudo naquilo que se refere às relações entre um editor e um escritor que adquiria capital simbólico (Bourdieu, 2001), como acompanhamos em Hetzel e Verne. No caso de Machado de Assis, depois das Crisálidas, livro de poemas de 1864, e dos Contos Fluminenses, 1869, uma coletânea de contos extraídas do Jornal das Famílias, os romances Ressurreição e O Manuscrito do Licenciado Gaspar, juntamente com as Histórias da Meia-Noite seriam os próximos três livros de ficção publicados por Machado na editora de Garnier. Para a comparação proposta por este artigo, interessa-nos, neste momento, a nova coletânea de contos extraída do Jornal das Famílias, as Histórias da Meia-Noite, que viriam a ser publicadas em 1873, sobretudo pela quarta cláusula do contrato. O contrato final corresponde a uma versão reestruturada do documento acima transcrito: ${ }^{7}$

\footnotetext{
${ }^{7}$ Este documento foi encontrado graças ao trabalho de pesquisa de fontes de Alexandra Pinheiro, que recuperou os "42 contratos e 33 recibos de transações efetivadas por Garnier" (2008, p. 175), os quais foram disponibilizados na página do site do Projeto Temático FAPESP "A circulação transatlântica dos impressos: a globalização da cultura no século XIX” (http://www.circulacaodosimpressos.iel.unicamp.br), por meio do trabalho de Marcia Abreu (coordenadora do projeto), Lúcia Granja (pesquisadora do projeto) e Lucas de Castro Marques (aluno do projeto). A história desses documentos é contada a seguir: depois da morte de B. L. Garnier (1893), os negócios da Livraria e Editora de B. L. Garnier foram transmitidos por herança a seu irmão, o livreiro-editor francês Hipollyte Garnier, que renovou os negócios no Rio de Janeiro e persistiu com a livraria e editora cariocas até o seu próprio fim, em 1911. Após essa época, o sobrinho-neto dos Garnier, Auguste-Pierre, deu continuidade aos mesmos negócios, até a Grande Depressão, em 1934, quando a livraria foi vendida a Ferdinand Briguiet (Hallewell, 2005). Nesse momento, iniciou-se a dispersão dos fundos da Editora Garnier, à medida em que Briguiet os vendeu à editora Martins de São Paulo e, também, à editora Jackson. No final da cadeia, foi Pedro Paulo Moreira, o editorproprietário da Vila Rica Editoras Reunidas, antiga Editora Itatiaia, quem guardou os documentos de Garnier, os quais lhe haviam chegado pela aquisição dos fundos da Editora Martins.
} 


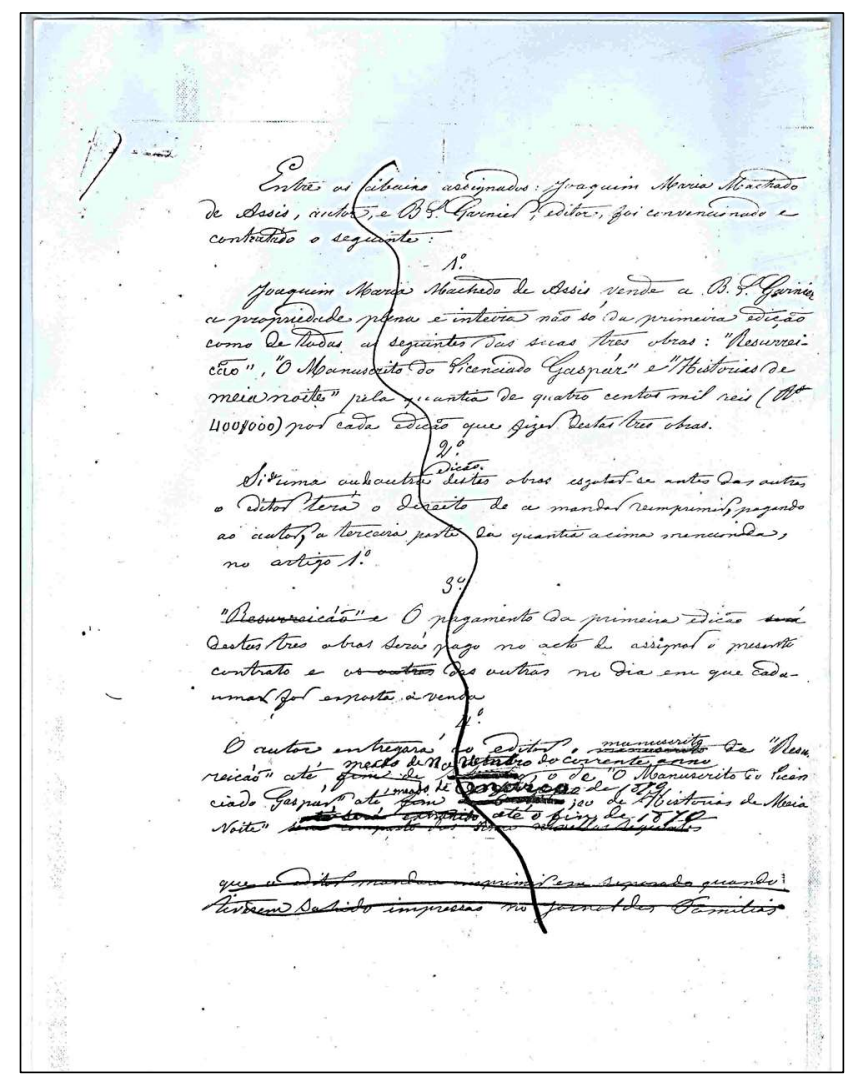

Fig.3 Imagem do rascunho do contrato de 30 de setembro de 1869. Documento acessível em: $<$ http://www.circulacaodosimpressos.iel.unicamp.br/arquivos/contratos_Garnier/Contrato_Machado_de_Assis_ Ressureicao_Man._Licenciado_Gaspar_Hist._Meia_Noite.pdffig $\backslash$ _ura $>$

A imagem anterior mostra que a quarta cláusula foi completamente alterada entre a versão em rascunho (constante dos documentos da Editora Vila Rica/Itatiaia) e a última versão dele, em posse do autor e de sua herdeira, limpa, transcrita pelo Catálogo da Exposição Machado de Assis, de 1839:

O autor entregará ao editor o manuscrito de "Ressurreição" até meados de novembro do corrente ano, o de "O Manuscrito do Licenciado Gaspar" até meados de março de 1870 (...), e o de "Histórias da Meia-Noite" até o fim e 1870 , composto pelas novelas seguintes [espaço] que o editor mandar imprimir em separado quando tiverem saído impressas no Jornal das Familias.

(30 de setembro de 1869) 


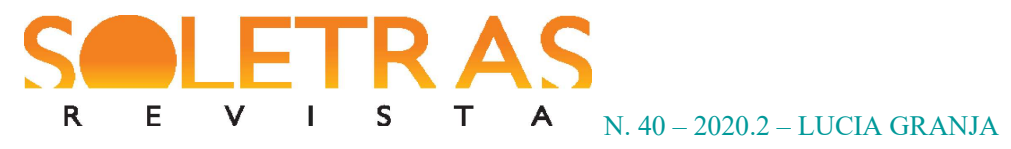

(Transcrição do rascunho do contrato de 30 de setembro de 1869. Documento acessível em: $<\mathrm{http}: / /$ www.circulacaodosimpressos.iel.unicamp.br/arquivos/contratos_Gar nier/Contrato_Machado_de_Assis_Ressureicao_Man._Licenciado_Gaspar_ Hist._Meia_Noite.pdffig $\overline{\text { lura }}>$. grifos nossos)

Comparando as duas versões, permanecem os prazos de entrega: dois romances e uma seleção de contos em pouco mais de um ano: “o autor entregará ao editor o manuscrito de Ressurreição até meado de novembro do corrente ano e O Manuscrito do Licenciado Gaspar até meados de março de 1870 e os das Histórias de Meia-Noite até o fim do ano de 1870". Porém, na versão do contrato em questão, após um espaço, estão riscadas as condições de composição de Histórias da Meia-Noite, por meio das quais, no rascunho, se havia escrito que seria Garnier quem escolheria as "novelas" que comporiam o volume, por entre as publicadas no Jornal das Famílias, "que o editor mandar imprimir em separado quando tiverem saído impressas no Jornal das Famílias”. Efetivamente, todas as novelas (ou contos) que compuseram o volume Histórias de Meia-Noite foram publicadas no Jornal das Famílias. ${ }^{8}$ Mas, ao contrário do que foi acordado entre Hetzel e Verne, é difícil acreditar que tenha sido Garnier, o editor, o responsável pela seleção das histórias que comporiam o segundo volume de contos daquele que se tornaria o mais célebre escritor brasileiro, o que é atestado pela versão "limpa" do contrato.

Em conclusão, além das estratégias semelhantes dos editores, as duas versões dos contratos brasileiros mostram que Machado de Assis insistiu, em relação a Garnier, em uma cláusula que Jules Verne, rumando para o auge de sua carreira, não pôde ou não teve interesse em alcançar, em relação seu editor, Hetzel. Desvantagem para Machado, Hetzel tinha disposição no trabalho pela internacionalização da obra Jules Verne restam alguns contratos assinados entre ambos que nos mostram que a negociação da tradução entendida como tarefa do editor, e não do autor, embora os direitos fossem igualmente divididos entre ambos (BEZERRA, 2018, p 86-7). ${ }^{9}$

\footnotetext{
${ }^{8}$ Os contos escolhidos para a coletânea, dentre os que Machado de Assis publicou no Jornal das Famílias, foram: "A parasita azul", 1872; "As bodas de Luis Duarte", 1873; "Ernesto de Tal”, 1873; "Aurora sem dia", 1870; "O relógio de outro", 1873 e "Pontos de vista", 1873.

${ }^{9}$ Como se disse, as relações entre Garnier e Hetzel, sobretudo no que toca à obra de Jules Verne, têm sido estudadas por Valéria Bezerra. Embora a pesquisadora ainda não a tenha publicado todos os detalhes dessa relação, foi ela quem descobriu que Hetzel cuidava da tradução dos romances de Verne, e que ambos dividiam os resultados financeiros disso.
} 


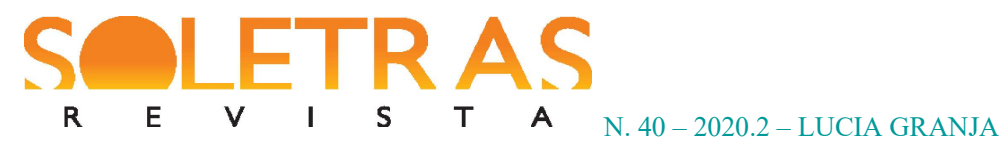

Este estudo comparativo tentou evidenciar, por meio da análise de documentos e de publicações em periódicos e livros, uma abordagem transnacional das estratégias editoriais e da produção literária, pois, para que compreendamos as tensões e os seus significados dentro de campos específicos (BOURDIEU, 1992), é necessário que consideremos, comparativamente, as trocas internacionais (CASANOVA, 1999). No que se refere ao consagradíssimo escritor brasileiro Machado de Assis, trabalha-se com a delicada tarefa de suplantar a ideia de que uma literatura nacional é apenas fruto da produção de um país, considerando os contatos, trocas, mediações, pensando também no movimento de homens e textos, com destaque, nesse último caso, para os periódicos.

\section{Referências}

BEZERRA, Valeria Cristina, "Tradução e literatura nacional: um estudo do empreendimento editorial de B. L. Garnier (1870-1880)". In: SOUZA, Roberto Acízelo de e MEDEIROS, Constantino Luiz (orgs). A história da literatura como problema: reflexões sobre crise permanente nos estudos diacrônicos sobre literature. Rio de Janeiro, Abralic, 2018, p. 85-99.

BOURDIEU, Pierre. A economia das trocas simbólicas. Trad. de Sérgio Miceli. $5^{\text {a }}$. ed. São Paulo: Perspectiva, 2001.

Les règles de l'art. Genèse et structure du champ littéraire. Paris: Seuil, 1992.

CASANOVA, Pascale. La République mondiale des Lettres. Paris: Seuil, 1999

Catálogo da Exposição Machado de Assis. Centenário do nascimento de Machado de Assis, 1839-1939. Rio de Janeiro, Ministério da Educação e Saúde, 1939 (Exposições II).

CHARTIER, Roger e MARTIN, Henri-Jean (orgs). Histoire de l'édition française. Le temps des éditeurs. Du Romantisme à Belle Époque. Vol. 3. Paris: Fayard; Cercle de la Librairie, 1990.

GRANJA, Lúcia e SANTANA Jr., Odair Dutra. Cânone literário e embates editoriais em duas coleções de literatura brasileira (1862-1876). Revista InterFACES. Rio de Janeiro, $\mathrm{n}^{\mathrm{O}} 29$ - vol. $2-$, p. 55-72, julho-dezembro de 2019.

GUIMARÃES, Valeria. Imprensa franco-brasileira e mediação: Rio de Janeiro e São Paulo, séculos XIX e XX. In: LUCA, Tania Regina de e GUIMARÃES, Valéria (orgs.). Imprensa estrangeira publicada no Brasil: primeiras incursões. São Paulo: CNPq e Rafael Copetti editor, 2017, p. 87-144. 
GUIRRA, Edmar. A trajetória de Jules Verne: a arte, o escritor e seu editor (tese de doutorado defendida no Programa de Pós-Graduação em Letras Neolatinas). UFRJ, Rio de Janeiro, 2016, $243 \mathrm{pp}$.

HALLEWELL, Laurence. O livro no Brasil: sua história. 2a . ed. Revista e ampliada. São Paulo: EdUSP, 2005.

MOLLIER, Jean-Yves. Uma livraria internacional no século XIX, a livraria Garnier Frères. Tradução de Willian Righini de Souza e Valéria Cristina Bezerra. In: GRANJA, Lúcia e De LUCA, Tania (orgs). Suportes e mediadores: a circulação transatlântica na literatura do século XIX (1889-1914). Campinas; São Paulo: Editora da UNICAMP, 2018, p. 33-54.

PINHEIRO, Alexandra. "Entre contratos e recibos: o trabalho de um editor francês no comércio livreiro do Rio de Janeiro oitocentista". In.: ABREU, Márcia (org). Trajetórias do romance: circulação, leitura e escrita nos séculos XVIII e XIX. Campinas-SP: Mercado das Letras, 2008.

WITKOWSKI, Claude. Le supplément littéraire detachable. In: Revue de la Bibliothèque Nationale, $\mathrm{n}^{\circ}$ 9, setembro/1983, $3^{\circ}$ ano, p. 3-10.

\section{Arquivos e Fontes:}

Diário do Rio de Janeiro, Rio de Janeiro, 1864-1865

Jornal das Famílias, Rio de Janeiro, 1864-1865

Magasin d'éducation et de récreation, Paris, 1858-1865

Musée des Familles, Paris, 1865-1878

Revista Popular, Rio de Janeiro, 1859-1860

www.gallica.bnf.fr/BNF

https://bndigital.bn.gov.br/hemeroteca-digital/

"Fundos Jules Verne", "Seção de Manuscritos" da Bibliothèque Nationale de France, site Richilieu

“Fundos Garnier", IMEC - Institut Mémoire de L'Édition Contemporaine, Abbaye d'Ardennes, Saint-Germain-la-Blanche-Herbe, França 


\title{
From magazines to books: Machado de Assis, Julio Verne, and their editors
}

\begin{abstract}
This article studies some aspects of the relationship between two editors (Baptiste-Louis Garnier and Pierre-Jules Hetzel) and two of their writers (respectively Machado de Assis and Jules Verne), a duo in France and another in Brazil. We demonstrate that many editorial actions of BaptisteLouis Garnier reveal that the methods for producing literary contents were the same in America and Europe. One of these methods was an expansion of the circulation of literary texts, from periodicals to books. Through this, we also discuss that "national literature" is not only the result of the production of a country, but the result of global contacts, cultural exchanges and actions of mediators. In this process, tensions arise between publishers and writers and comparing Machado de Assis and Julio Verne relations with their publishers discloses aspects of their trajectories of consecration and acquisition of symbolic capital, according to Bourdieu's concepts.
\end{abstract}

Keywords: Baptiste-Louis Garnier; publishing; world literature; Machado de Assis; symbolic capital.

Recebido em: 30 de maio de 2020 .

Aceito em: 28 de agosto de 2020. 